\title{
The Effect of Cortex Lycii on Rattus norvegicus' Blood Glucose Level Using a High Glucose Diet
}

\author{
Hongping Tan, Cristian Vinanzaca \\ John Bowne High School, Flushing, NY, USA \\ Email: Hongping.tan123@gmail.com
}

How to cite this paper: Tan, H.P. and Vinanzaca, C. (2018) The Effect of Cortex Lycii on Rattus norvegicus Blood Glucose Level Using a High Glucose Diet. Journal of Diabetes Mellitus, 8, 160-170. https://doi.org/10.4236/jdm.2018.84016

Received: May 21, 2018

Accepted: November 16, 2018

Published: November 19, 2018

Copyright (๑) 2018 by authors and Scientific Research Publishing Inc. This work is licensed under the Creative Commons Attribution International License (CC BY 4.0).

http://creativecommons.org/licenses/by/4.0/ c) (i) Open Access

\begin{abstract}
One of the primary problems in the United States is diabetes. Cortex Lycii is an herb from Asia mostly used in traditional Chinese medicine. Although its main purpose is not for lowering blood glucose levels, there are studies on Cortex Lycii with other substances which have proven it can lower glucose level in type 2 diabetes rat. Unlike other experiments, this experiment only used Cortex Lycii as a single unit to see if there was any effect on blood glucose level. Also an observation was done on if Cortex Lycii could reduce blood glucose level after ingesting a high glucose diet. Rattus norvegicus was used in this project and in order for the subject to consume Cortex Lycii, the herb was boiled and the liquid was given for consumption. In order to increase the rats' glucose levels, corn syrup and white sugar were added to the mixture. The data showed significant decrease of blood glucose when Cortex Lycii liquid was ingested. This research has shown that Cortex Lycii can be a potential treatment for hyperglycemia or diabetes. With further research, there can be an alternative treatment rather than injecting external hormones (Insulin).
\end{abstract}

\section{Keywords}

Cortex Lycii, Diabetes, Blood Glucose Level, Health, Hyperglycemia

\section{Introduction}

Currently, diabetes is one of the top 10 causes of leading deaths in United States. The most common sign of having diabetes is hyperglycemia. Hyperglycemia is described as having abnormally high blood glucose level. Over time, having hyperglycemia can lead to organ damage. The reason behind type 2 diabetes and hyperglycemia is the body not producing enough insulin for glucose intake. When human takes foods, the foods are broken down into glucose. When glu- 
cose enters the bloodstream, the pancreas secretes insulin to keep the glucose level down. Insulin is a hormone that signals the cells that lack energy to accept glucose into their cell wall. When not enough insulin hormones are produced, glucose is unable to diffuse cells and causes the bloodstream to have high levels of glucose. Since the cells are not getting enough glucose, they are weakened. Blood glucose level can be tested using a glucometer. Small amounts of blood can be collected using a lance and a test strip. The current treatment for hyperglycemia is injecting insulin into bloodstream.

This study has the potential to find alternative treatment for hyperglycemia to combat diabetes. Using Rattus norvegicus as test subject is the most efficient way to test a treatment without using human as test subjects. Giving rats a high glucose diet will cause them to have hyperglycemia. Then feeding them cortex lycii liquid and comparing it with the control group without cortex lycii will show the effects of cortex lycii on blood glucose. Rat's blood can also be tested using human glucometer. If rats from the experimental group show lower glucose level than the control group when both of them consume high glucose diet, then it will prove Cortex Lycii can stimulate higher insulin production.

This experiment was designed to find an alternative treatment for hyperglycemia. The findings from this experiment can be followed up with further studies on diabetes. Another objective of this study was to observe the effect of high glucose diet on Rattus norvegicus. Since many researches have found the connection between unhealthy diets with diabetes, this experiment could show cortex lycii having a diabetes prevention effect. Last objective of this study was to observe if there are side effects of using cortex lycii. Based on other research, this herb has shown no side effects [1].

\section{Materials}

\begin{tabular}{|c|c|}
\hline Items & Subtotal \\
\hline 4 Plastic Large Rat Cages $20 \times 16 \times 8$ & $\begin{array}{l}\text { Large Rat Cages at John Bowne } \\
\text { High School Agriculture department } \\
\qquad \$ 0.00\end{array}$ \\
\hline 8 Rats (Rattus norvegicus) & $\begin{array}{l}\text { Rats were provided by John Bowne } \\
\text { High School Agriculture department }\end{array}$ \\
\hline Rat Food 50 Lb Mazon: Rat Pallets & $\begin{array}{l}\text { Provided by John Bowne } \\
\qquad \$ 0.00\end{array}$ \\
\hline Hot Plate & $\begin{array}{l}\text { Provided by John Bowne } \\
\qquad \$ 0.00\end{array}$ \\
\hline Pot & $\begin{array}{l}\text { Provided by John Bowne } \\
\qquad \$ 0.00\end{array}$ \\
\hline $580 \mathrm{~mL}$ Water Bottles & $\begin{array}{l}\text { Provided by John Bowne } \\
\qquad \$ 0.00\end{array}$ \\
\hline $\begin{array}{c}\text { Bayer Contour Meter, } 50 \text { Contour Test Strips, } \\
100 \text { Slight Touch } 30 \text { Gauge Lancets, } \\
1 \text { Lancing Device, } 100 \text { Alcohol Prep Pads. }\end{array}$ & $\begin{array}{l}\text { Amazon } \\
\$ 40.00\end{array}$ \\
\hline
\end{tabular}




\begin{tabular}{cc}
\hline 2 Cartel Corn Syrup & Provided by John Bowne \\
Domino Sugar & $\$ 13.00$ \\
& Supermarket \\
Measuring Cup $(1$ liter $)$ & $\$ 4.00$ \\
& Provided by John Bowne \\
Digital Weighing Scale & $\$ 0.00$ \\
& Provided by John Bowne \\
3 Lb of Cortex lycii herb & $\$ 0.00$ \\
& Chinese herbal store \\
& $\$ 24.00$ \\
& Total cost: $\$ 81.00$ \\
\hline
\end{tabular}

\section{Methodology}

\subsection{Blood Testing}

1) Use alcohol wipes to disinfect the tail of the rat.

2) Use lancet to prick a small visible amount of blood from the rat's tail.

3) Use test strip to collect the blood sample and wait for the glucometer to give a reading.

4) Repeat the blood test for all 8 rats.

5) Record down the data for each group of 4 rats.

6) Compare the blood glucose level of Cortex Lycii group with the normal water group.

7) Repeat for 3 trials.

\subsection{Feeding}

1) Soak 50 grams of Cortex Lycii in 1 liter of water for 10 minutes, then boil for 30 minutes.

2) After Cortex Lycii liquid cool down to room temperature, it is poured into $580 \mathrm{~mL}$ water bottle mixed in with sugar and high fructose corn syrup.

3) For experimental group, the Cortex Lycii bottle is given to 4 Rattus norvegicus along with their 3 pellets/animal of food.

4) For control group, the other 4 Rattus norvegicus are given normal water with sugar and syrup along with the same food.

5) Wait for 2 days for food consumption.

6) For trial 1 only 25 grams of syrup was given. For trial 2 and 3, 25 gram of syrup and 25 gram of sugar was given.

7) Compare the rise in blood glucose when higher glucose diet was given.

\subsection{Literature Review}

Currently based on statistics provided by the CDC (National Center for Chronic Disease Prevention and Health Promotion), more than 30.3 million Americans have diabetes which is more than $9 \%$ of the population [2]. In an experiment conducted on Diabetes epidemic by Mokdad, Bowman, Ford, Vinicor, Marks 
and Koplan, it was explained that diabetes is one of the leading causes of death in the United States. The two types of diabetes (type 1 and type 2) both can be treated with insulins [3]. They have similar results on the body, however, type 2 diabetes can be caused by weight gain and physical inactivity [4]. Physical inactivity is defined as not getting recommended level of physical exercises. The $\beta$-cell apoptosis occurs when the body becomes inactive. However, type 1 is mostly inherited through genetic [5]. Based on a research on type 2 diabetes, the amount of patients is expected to double by 2030 [6].

The only medical treatment currently available for diabetic patients is insulin treatment. Due to $\beta$-cell not producing enough insulin, injection of insulin is used as a treatment. Patient can take the insulin injection, when they have high blood glucose. Insulin is used to combat hyperglycemia [7] [8]. Hyperglycemia is an abnormal blood glucose level. There are other treatments, however, many of them have insufficient research to support their effects [9].

Testing the effect of Cortex Lycii on high blood glucose rats could lead to a new breakthrough in the field of agriculture. Agriculture is the cultivation of animal and plants to benefit more humans. The result of this experiment could lead to more production of the herb Cortex Lycii and enhancing diabetic researches. Finding new treatments for hyperglycemia could lead to less people suffering from the symptoms of diabetes.

Cortex Lycii is an herb that is used in traditional Chinese herbal medicine formulas [10]. It is not well known in western treatments and little research has been done on this herb. In the experiment by Chan, Lam, Leung, Che, and Fung tested a formula labeled SR10 was tested on type 2 diabetic mice. In SR10 one of the content listed was Cortex Lycii. The results showed it lowered blood glucose level and the SR10 did not exhibit any toxic effect to the mice. Another experiment conducted by different scientists on diabetic patients with different symptoms. The patients were given an herbal treatment with Cortex Lycii included as part of its content. The result showed some of the symptoms were being relieved [11]. Further research was done on Cortex Lycii by Ye, Huang, Ni, and Wang where the scientists compared the effectiveness of aqueous extracts to ethanol extracts of Cortex Lycii in elevating insulin sensitivity [12]. There is currently no found research done on the testing Cortex Lycii as a single unit on diabetic patients. Most research on Cortex Lycii is mixing this herb with many other substances to view their combined effect. Cortex Lycii has more benefits than just a treatment for diabetes. Research done by $\mathrm{Li}, \mathrm{Hu}$, Huang, Han, and Cheung, concluded that Cortex Lycii extract contained a chemical compound that was effective in preventing cell damage [13]. In the few other researches, the chemical compounds of cortex lycii were further broken down [12] [14]. The compound Kukoamine B found in the herb has antibacterial effects. The compound lycimins A and B was also found to have Anti-ACE effect. ACE is an angiotensin converting enzyme which raises blood pressure. Lyciminis $A$ and $B$ are types of ACE inhibitor. ACE inhibitors can reduce heart failures [15]. 
Diabetes can cause other vascular diseases. Since diabetes cause abnormal metabolism of triglyceride-rich lipoproteins, diabetic patients have increased risk of atherosclerosis [16]. Cortex Lycii also has a suppression effect on atherosclerosis. Atherosclerosis is a buildup of fat and cholesterol that causes blockage in blood flow. Cortex Lycii has an effect on slowing blood cell hemolysis and LDL (low-density lipoprotein) oxidation which can lessen the risk of atherosclerosis [17].

Although research on Cortex Lycii is limited, there has been other research on testing different substances on diabetes [18]. Tsuneki, Ishizuka, Wu, Sasaoka, and Kimura conducted a research on green tea effects on diabetic mice. After letting the diabetic mice ingest green tea, blood glucose levels were tested after 2 - 6 hours. The result shows their blood glucose levels were lowered. Similar tests could be done on the rats with Cortex Lycii replacement of green tea [19]. There are other herbs that researchers have tested for diabetes treatments. Panax ginseng was tested on type 2 diabetic mice and resulted in enhancing insulin sensitivity. By improving insulin, the blood glucose level was also lowered [20]. In another experiment Corni Fructus and Lycii Radicis Cortex were combined and tested on diabetic rats. The results also showed improvement in blood glucose levels [21]. Codonopsis javanica root is also used in Chinese traditional medicine, and was tested on fructose-fed insulin resistant rats. The finding was that fructose intake can damage cell function and this herb can significantly improve the antioxidant enzyme activities [22]. In 2005, an experiment with Mangiferin on diabetic rats was done. The drugs showed significant effect on lowering plasma glucose level. This drug is extracted from the plant Mangifera indica [23]. This means that future research in developing new drugs, plants can also be part of the research.

Lastly, in order to successfully test blood glucose levels, research on blood drawing procedures was done. There are few ways to draw small amounts of bloods from rats. Some locations where blood can be collected are saphenous vein, dorsal pedal vein, and tail vein [24] However, this research mostly shows the collection of large amount of blood sample. In a glucose test, the glucometer only requires $0.5 \mu \mathrm{l}$. For minimal stress to the rat drawing blood from the tail is the most ideal [25]. To increase blood flow rats can be placed in warm water [26]. Based on IACUC blood sample guidelines, rats should not have more than $2.0 \mathrm{~mL}$ of blood drew in 24-hour time period [27]. To keep this experiment constant, only male rats were used. Identifying the sex of the rat was done by looking at the anogenital distance. Male rats have a longer a longer anogenital than females [28]. Diabetic male rats tend to show increasing blood glucose more early on than female [14]. Also male rats show early symptom of body weight and are more susceptible to early symptoms of diabetes [29].

In summary of all these studies conducted on diabetes, the current insulin treatment is not the only way to treat hyperglycemia. Many herbs that were tested for their effectiveness against diabetic patients, showed a positive effect. Cortex Lycii is one of the herbs that showed up several of different studies. This 
could mean Cortex Lycii is one of the key factors of lowering blood glucose. Further experiments and researches should be done on this herb to support or reject this theory. If it is supported, then a new treatment for diabetes could be discovered in the near future.

\section{Discussion}

Trial 1 of the experiment was used to compare the blood glucose of the control group with the experimental group (Table 1). The rats' diet included 25 grams of corn syrup mixed in their water. The control group received 25 grams of corn syrup with normal water in a $580 \mathrm{~mL}$ water bottle. The experimental group received 25 grams of corn syrup with Cortex Lycii liquid in $580 \mathrm{~mL}$ water bottle. When the trial ended, the results showed that the control group had a higher blood glucose level than the experimental group. However, the result didn't show enough differences in the blood glucose level. To view the effect of Cortex Lycii on blood glucose, more significant changes in glucose levels were needed. Therefore, in trial 2, white sugar was added to both control and experimental group to increase their glucose intake (Table 2). Within the increase of glucose in the rats' diet, the data presents the control group had a significant increase to their blood glucose levels. Due to the increase of blood glucose in the control group, the data shows rats in the experimental group had significantly lower blood glucose levels compared to the control group. With the increase of glucose intake, only the rats that drank Cortex Lycii showed no significant increase to their blood glucose levels. To confirm that the data collected from trial 2 was accurate, trial 3 was conducted with the same variable (Table 3). As shown in Figure 1, the average differences between experimental group and control group of trial 2 and 3 are similar. With the same diet of 25 grams of white sugar and 25 grams of corn syrup, both rats' blood glucose levels from trial 2 and 3 increased similarly from trial 1 . This proves that white sugar can increase blood glucose levels significantly when added to a diet. Since the data from trial 2 and 3 are constant, it indicated the trials were run accurately (Figure 2).

Table 1. Trial 1 with 25 grams of syrup mixed into rats' drinking water.

\begin{tabular}{cc}
\hline Control group & Experimental group \\
\hline Rat $1: 143 \mathrm{mg} / \mathrm{dL}$ & Rat $1: 124 \mathrm{mg} / \mathrm{dL}$ \\
Rat $2: 110 \mathrm{mg} / \mathrm{dL}$ & Rat $2: 85 \mathrm{mg} / \mathrm{dL}$ \\
Rat $3: 117 \mathrm{mg} / \mathrm{dL}$ & Rat $3: 113 \mathrm{mg} / \mathrm{dL}$ \\
Rat $4: 127 \mathrm{mg} / \mathrm{dL}$ & Rat $4: 99 \mathrm{mg} / \mathrm{dL}$ \\
\hline
\end{tabular}

Table 2. Trial 2 with 25 grams of syrup and 25 grams of white sugar in drinking water.

\begin{tabular}{cc}
\hline Control group & Experimental group \\
\hline Rat $1: 255 \mathrm{mg} / \mathrm{dL}$ & Rat $1: 116 \mathrm{mg} / \mathrm{dL}$ \\
Rat $2: 146 \mathrm{mg} / \mathrm{dL}$ & Rat $2: 103 \mathrm{mg} / \mathrm{dL}$ \\
Rat $3: 143 \mathrm{mg} / \mathrm{dL}$ & Rat $3: 120 \mathrm{mg} / \mathrm{dL}$ \\
Rat $4: 141 \mathrm{mg} / \mathrm{dL}$ & Rat $4: 119 \mathrm{mg} / \mathrm{dL}$ \\
\hline
\end{tabular}


Table 3. Trial 3 with 25 grams of syrup and 25 grams of white sugar in drinking water.

\begin{tabular}{cc} 
Control group & Experimental group \\
\hline Rat $1: 135 \mathrm{mg} / \mathrm{dL}$ & Rat $1: 103 \mathrm{mg} / \mathrm{dL}$ \\
Rat $2: 144 \mathrm{mg} / \mathrm{dL}$ & Rat $2: 92 \mathrm{mg} / \mathrm{dL}$ \\
Rat $3: 155 \mathrm{mg} / \mathrm{dL}$ & Rat $3: 111 \mathrm{mg} / \mathrm{dL}$ \\
Rat $4: 178 \mathrm{mg} / \mathrm{dL}$ & Rat $4: 114 \mathrm{mg} / \mathrm{dL}$ \\
\hline
\end{tabular}

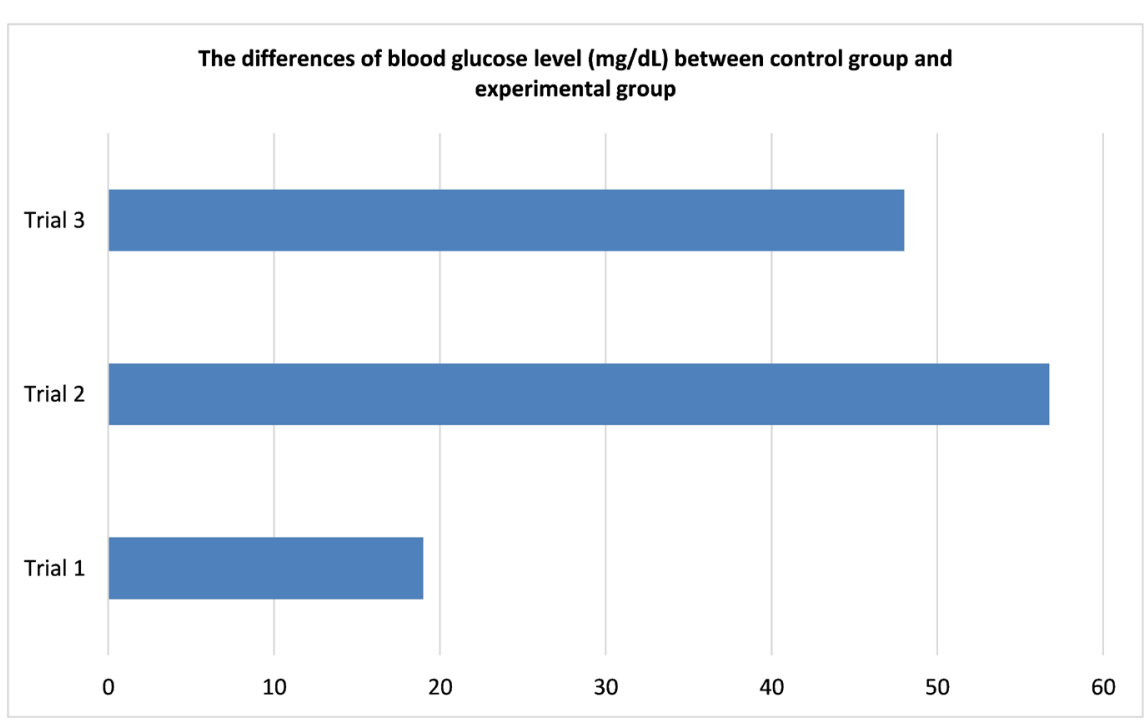

Figure 1. This graph represents the difference of blood glucose level $(\mathrm{mg} / \mathrm{dL})$ over 3 trials.

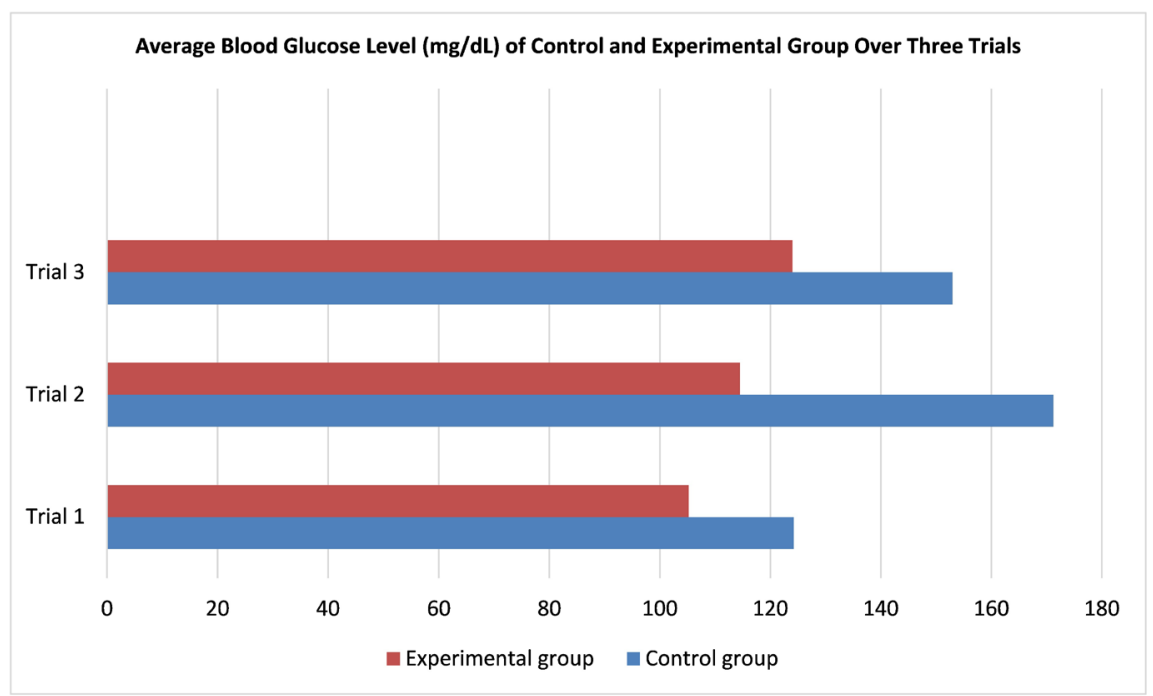

Figure 2. This graph shows average blood glucose level of both subject groups over the 3 trials.

Research done by Chan, Lam, Leung, Che, and Fung, proved that Cortex Lycii with other herbs can stimulate insulin production. The experiment done by them was on type 2 diabetic rats with a dysfunctional pancreas. The data pro- 
vided by this research also supports their hypothesis of Cortex Lycii that can stimulate pancreas $\beta$-cells production of insulin. By increasing the production of insulin, this would cause blood glucose levels to decrease. This experiment was able to test the effect of Cortex Lycii by testing blood glucose levels. Since type 2 diabetes means the body is not producing enough insulin to keep blood glucose levels normal, and Cortex Lycii can increase insulin production, then with further research Cortex Lycii has the potential for type 2 diabetes treatment. At the end of the research, no rats from the experimental group showed any signs of lethargy or intoxicated behaviors. This also supports the experiment done by researchers, Chan, Lam, Leung, Che, and Fung which has discussed Cortex Lycii does not have any toxic effects [2]. One observation of the 8 rats is the difference in sizes of the control group compared to the experimental group. The rats that did not receive the Cortex Lycii and only high glucose diet were significantly larger in size, close to being obese. This result was similar to the experiment done by other scientist who showed that Cortex Lycii helps prevent obesity [30]. The rats that received Cortex Lycii and also had the same high glucose diet were smaller in size and similar to an average rat. Because the nature of this experiment is on blood glucose, no weighing test was done on the rats.

One challenge faced in this experiment is the small sample size. Due to time limitation, this experiment was only able to test 8 rats per trial over 3 trials. However, with the trials that were conducted, the data presented was highly constant and showed a significant difference of blood glucose levels to reach a conclusion. A minor problem faced in this experiment was the difficulties of collecting blood sample from the rats. The lancet in the blood glucose kit was meant for human use, so the needle was not able to prick through the skin of the rats' tough tail. After some few failures, the cap of the pen was removed to increase the depth of the lancet. This method of collecting blood was then used for rest of the trials.

The main purpose in studies of agriculture is to benefit people through the use of plants and animals. This research can benefit the agriculture field due to the potential medical advancement on diabetic treatment. Since current treatment for lack of insulin is to inject body with more insulin, with further research Cortex Lycii could be an alternative treatment due to its ability to stimulate pancreas to produce its own insulin rather than injecting external hormone. This could be a potential market for growers to become a part. Growing the Cortex Lycii herb can increase jobs, as well as profit for farmers and plant producers.

\section{Acknowledgements}

The John Bowne agriculture department provided funding and animals for this experiment. Both authors Hongping Tan and Cristian Vinanzaca were the main experimenters and did all the actions listed in the procedure. Both authors wrote in this manuscript and research data. Some assistance was provided by Raj Patel and Sebastian Wirawan for recording some of data in the glucometer while 
blood sample was being collected. Erika Asitimbay and Karen Cruz cleaned the rat's cages when time was limited. Chelsea Aviles assisted in boiling Cortex lycii for the rats. Karla Bunay assisted with restraining the rats while collecting blood sample from the rats from time to time. Ms. Weinstein assisted by breeding the amount of rats needed for the project. Ms. Jamiolkowska assisted by purchasing the materials needed for the project and edited this paper. There is no conflict of interest in this experiment, as everyone was credited for their attribution. Ms Jamiolkowska, the instructor of this experiment, will be the guarantor of this work, as such, had full access to all the data in the study and takes responsibility for the integrity of the data and the accuracy of the data analysis.

\section{Conflicts of Interest}

The authors declare no conflicts of interest regarding the publication of this paper.

\section{References}

[1] Chan, J.Y., Lam, F., Leung, P., Che, C. and Fung, K. (2008) Antihyperglycemic and Antioxidative Effects of a Herbal Formulation of Radix Astragali, Radix Codonopsis and Cortex Lycii in a Mouse Model of Type 2 Diabetes Mellitus. Phototherapy Research, 23, 658-665. http://onlinelibrary.wiley.com/doi/10.1002/ptr.2694/full

[2] National Diabetes Statistics Report, 2017. (2017) https://www.cdc.gov/diabetes/pdfs/data/statistics/national-diabetes-statistics-report. pdf

[3] Mokdad, A.H., Bowman, B.A., Ford, E.S., Vinicor, F., Marks, J.S. and Koplan, J.P. (2001) The Continuing Epidemics of Obesity and Diabetes in the United States. JAMA, 286, 1195-1200. https://doi.org/10.1001/jama.286.10.1195

[4] Lee, I.M., Shiroma, E.J., Lobelo, F., Puska, P., Blair, S.N., Katzmarzyk, P.T., Lancet Physical Activity Series Working Group. (2012) Effect of Physical Inactivity on Major Non-Communicable Diseases Worldwide: An Analysis of Burden of Disease and Life Expectancy. Lancet, 38, 219-229. https://www.ncbi.nlm.nih.gov/pubmed/22818936

[5] Tuomi, T. (2005) Type 1 and Type 2 Diabetes. http://diabetes.diabetesjournals.org/content/54/suppl_2/S40

[6] Vijan, S. (2010) Type 2 Diabetes. http://annals.org/aim/article-abstract/745650/type-2-diabetes

[7] Garvey, W.T., Olefsky, J.M., Griffin, J., Hamman, R.F. and Kolterman, O.G. (1985) The Effect of Insulin Treatment on Insulin Secretion and Insulin Action in Type II Diabetes Mellitus. Diabetes, 34, 222-234. http://diabetes.diabetesjournals.org/content/34/3/222.short

[8] Kasuga, M. (2006) Insulin Resistance and Pancreatic $\beta$ Cell Failure. Journal of Clinical Investigation, 116, 1756-1760. https://doi.org/10.1172/JCI29189

[9] Ghorbani, A. (2014) Clinical and Experimental Studies on Polyherbal Formulations for Diabetes: Current Status and Future Prospective. Journal of Integrative Medicine, 12, 336-345.

http://www.sciencedirect.com/science/article/pii/S2095496414600315?via\%3Dihub

[10] Gao, J., Liu, Z.J., Chen, T. and Zhao, D. (2014) Pharmaceutical Properties of Caly- 
cosin, the Major Bioactive Isoflavonoid in the Dry Root Extract of Radix astragali. Pharmaceutical Biology, 52, 1217-1222.

http://www.tandfonline.com/doi/full/10.3109/13880209.2013.879188

[11] Su, K., Zhu, F., Guo, L., Zhu, Y., Li, W. and Xiong, X. (2013) Retrospective Study on Professor Zhongying Zhou's Experience in Traditional Chinese Medicine Treatment on Diabetic Nephropathy. Journal of Traditional Chinese Medicine, 33, 262-267.

http://www.sciencedirect.com/science/article/pii/S0254627213601375?via\%3Dihub

[12] Yahara, S., Shigeyama, C., Nohara, T., Okuda, H., Wakamatsu, K. and Yasuhara, T. (1989) Structures of Anti-Ace and -Renin Peptides from Lyciiradicis Cortex. Tetrahedron Letters, 30, 6041-6042.

http://www.sciencedirect.com/science/article/pii/S0040403901938493

[13] Li, Y., Hu, S., Huang, Y., Han, Y. and Cheung, H. (2015) Preventing $\mathrm{H}_{2} \mathrm{O}_{2}$-Induced Toxicity in Primary Cerebellar Granule Neurons via Activating the PI3-K/Akt/ GSK3 $\beta$ Pathway by Kukoamine from Lycii Cortex. Journal of Functional Foods, 17, 709-721. http://www.sciencedirect.com/science/article/pii/S1756464615003230\#

[14] Liu, X., Zheng, X., Long, Y., Cao, H., Wang, N., Lu, Y., et al. (2011) Dual Targets Guided Screening and Isolation of Kukoamine B as a Novel Natural Anti-Sepsis Agent from Traditional Chinese Herb Cortex Lycii. International Immunopharmacology, 11, 110-120.

http://www.sciencedirect.com/science/article/pii/S1567576910003449

[15] Yusuf, S., et al. (2000) Effects of an Angiotensin-Converting-Enzyme Inhibitor, Ramipril, on Cardiovascular Events in High-Risk Patients. New England Journal of Medicine, 342, 145-153.

[16] Tomkin, G.H. (2010) Atherosclerosis, Diabetes and Lipoproteins. Expert Review of Cardiovascular Therapy, 8, 1015-1029. https://doi.org/10.1586/erc.10.45 http://www.tandfonline.com/doi/abs/10.1586/erc.10.45

[17] Chan, J.Y., Koon, J.C., Leung, P., Che, C. and Fung, K. (2011) Suppression of Low-Density Lipoprotein Oxidation, Vascular Smooth Muscle Cell Proliferation and Migration by a Herbal Extract of Radix astragali, Radix codonopsis and Cortex lycii. BMC Complementary and Alternative Medicine, 11, 32.

https://bmccomplementalternmed.biomedcentral.com/articles/10.1186/1472-6882-1 $\underline{1-32}$ https://doi.org/10.1186/1472-6882-11-32

[18] He, K., Li, X., Chen, X., Ye, X., Huang, J., Jin, Y. and Shu, H. (2011) Evaluation of Antidiabetic Potential of Selected Traditional Chinese Medicines in STZ-Induced Diabetic Mice. Journal of Ethnopharmacology, 137, 1135-1142. http://www.sciencedirect.com/science/article/pii/S0378874111005095?via\%3Dihub\# fig0025 https://doi.org/10.1016/j.jep.2011.07.033

[19] Tsuneki, H., Ishizuka, M., Wu, J., Sasaoka, T. and Kimura, I. (2004) Effect of Green Tea on Blood Glucose Levels and Serum Proteomic Patterns in Diabetic $(\mathrm{db} / \mathrm{db})$ Mice and on Glucose Metabolism in Healthy Humans. BMC Pharmacology, 4, 18. https://bmcpharma.biomedcentral.com/articles/10.1186/1471-2210-4-18 https://doi.org/10.1186/1471-2210-4-18

[20] Yeo, J., Kang, Y., Cho, S. and Jung, M. (2011) Effects of a Multi-Herbal Extract on Type 2 Diabetes. Chinese Medicine, 6, 10. https://doi.org/10.1186/1749-8546-6-10 https://cmjournal.biomedcentral.com/articles/10.1186/1749-8546-6-10

[21] Oh, T.W., Kang, S.Y., Kim, K.H., Song, M. and Park, Y. (2013) Anti-Diabetic Effect 
of Medicinal Plants Used for Lower Wasting-Thirst in Streptozotocin-Induced Diabetic Rats. The Korea Journal of Herbology, 28, 53-60.

http://koreascience.or.kr/article/ArticleFullRecord.jsp?cn=DHBCBU_2013_v28n5_ $\underline{53}$

https://doi.org/10.6116/kjh.2013.28.5.53

[22] Chen, K., Peng, W., Hou, C., Chen, C., Chen, H., Kuo, C. and Korivi, M. (2013) Codonopsis javanica Root Extracts Attenuate Hyperinsulinemia and Lipid Peroxidation in Fructose-Fed Insulin Resistant Rats. Journal of Food and Drug Analysis, 21, 347-355. http://www.jfda-online.com/article/S1021-9498(13)00048-3/fulltext https://doi.org/10.1016/j.jfda.2013.08.001

[23] Muruganandan, S., Srinvasan, K., Gupta, S., Gupta, P. and Lal, J. (2005) Effect of Mangiferin on Hyperglycemia and Atherogenicity in Streptozotocin Diabetic Rats. Journal of Ethnopharmacology, 97, 497-501.

http://www.sciencedirect.com/science/article/pii/S0378874105000097 https://doi.org/10.1016/j.jep.2004.12.010

[24] Parasuraman, S., Raveendran, R. and Kesavan, R. (2010) Blood Sample Collection in Small Laboratory Animals. Journal of Pharmacology and Pharmacotherapeutics, 1 , 87-93. https://www.ncbi.nlm.nih.gov/pmc/articles/PMC3043327/ https://doi.org/10.4103/0976-500X.72350

[25] Lee, G. and Goosens, K.A. (2015) Sampling Blood from the Lateral Tail Vein of the Rat. Journal of Visualized Experiments, No. 99, Article No. 52766.

https://www.ncbi.nlm.nih.gov/pmc/articles/PMC4542852/ https://doi.org/10.3791/52766

[26] Stewart, K. and Schroeder, V.A. (2018) Blood Withdrawal I. https://www.jove.com/science-education/10246/blood-withdrawal-i

[27] Office of Animal Resources Institutional Animal Care and Use Committee (n.d.). https://animal.research.uiowa.edu/iacuc-guidelines-blood-collection

[28] Quesenberry, K.E., Donnelly, T.M. and Mans, C. (2012) Chapter 22 Biology, Husbandry, and Clinical Techniques of Guinea Pigs and Chinchillas. In: Quesenberry, K.E. and Carpenter, J.W., Eds., Ferrets, Rabbits, and Rodents. Clinical Medicine and Surgery, Elsevier, Amsterdam, 279-294.

https://www.sciencedirect.com/science/article/pii/B9781416066217000221 https://doi.org/10.1016/B978-1-4160-6621-7.00022-1

[29] Cortright, R.N., Collins, H.L., Chandler, M.P., Lemon, P.W. and Dicarlo, S.E. (1999) Diabetes Reduces Growth and Body Composition More in Male than in Female Rats. Physiology \& Behavior, 60, 1233-1238.

http://www.sciencedirect.com/science/article/pii/S0031938496002223 https://doi.org/10.1016/S0031-9384(96)00222-3

[30] Ye, Z., Huang, Q., Ni, H.X. and Wang, D. (2008) Cortex Lycii Radicis Extracts Improve Insulin Resistance and Lipid Metabolism in Obese-Diabetic Rats. Phytotherapy Research, 22, 1665-1670. https://doi.org/10.1002/ptr.2552

http://onlinelibrary.wiley.com/doi/10.1002/ptr.2552/full 